\title{
A Propósito do Artigo "Adults with Down Syndrome: Characterization of a Portuguese Sample"
}

\author{
Regarding the Article "Adults with Down Syndrome: Characterization of a \\ Portuguese Sample"
}

Jorge M. SARAIVA ${ }^{1,2,3}$

Acta Med Port 2014 May-Jun;27(3):281-281

Palavras-chave: Adulto; Síndrome de Down, Portugal.

Keywords: Adult; Down Syndrome; Portugal.

O número de pessoas com necessidades especiais em cuidados de saúde tem aumentado de modo significativo em resultado da maior sobrevida, diagnóstico e identificação de necessidades específicas. $O$ acompanhamento e a aplicação das normas de orientação para promoção e vigilância da saúde exige conhecimentos, aptidões e atitudes a todos os médicos: os que são os médicos assistentes dos doentes e os que são envolvidos enquanto especialistas numa patologia específica na prestação de cuidados a um grupo em que esta tem uma frequência ou características particulares.

Para convencer os mais relutantes bastará recordar que 6 a $8 \%$ da população é afetada por uma doença rara (cada uma com uma frequência inferior a 1 para 2000 mas em número superior a oito mil). A presença deste grupo de pessoas entre os utentes do sistema de saúde é ainda amplificada pela natureza e gravidade das suas necessidades específicas em cuidados de saúde.

Um grande número destas doenças é diagnosticada em idade pediátrica. Nestas situações há também que assegurar a transição dos cuidados médicos hospitalares de um ambiente pediátrico para um espaço de adultos, garantindo a qualidade e a continuidade de cuidados, em complemento com a indispensável supervisão do especialista em medicina geral e familiar - que terá entre os seus utentes aproximadamente uma centena de pessoas com doenças raras.

A trissomia 21 não é uma doença rara mas exemplifica bem os desafios anteriormente enumerados e o artigo agora publicado por Paula Breia et al com o título "Adults with Down Syndrome: characterization of a portuguese Sample"1 merece ser analisado também enquanto estudo de caso com grande utilidade para outras patologias.

\section{REFERÊNCIAS}

1. Breia P, Mendes R, Silvestre A, Gonçalves MJ, Figueira MJ, Bispo R. Adults with Down Syndrome: Characterization of a Portuguese sample. Acta Med Port. 2014;27:357-363.

2. Bull MJ. Clinical report - health supervision for children with Down Syndrome. Pediatrics. 2011;128:393-406.

Seleciono apenas três aspetos que merecem profunda reflexão:

- a facilidade de identificação apenas numa região de Portugal de um grupo de 209 adultos com o diagnóstico confirmado de trissomia $21^{1}$;

- a contradição entre o conhecimento dos cuidados de promoção, prevenção e vigilância da saúde específicos, ${ }^{2,3}$ a existência de um grupo de 209 pessoas com essas necessidades identificadas e o contraste com a negação dos cuidados uma vez que não têm vigilância médica regular ${ }^{1}$;

- o abandono pelo sistema de saúde português ocorre após a idade pediátrica ${ }^{1}$ traduzindo o insucesso da transferência de cuidados para espaços de adultos, possivelmente pelo incumprimento dos procedimentos recomendados para esta situação. ${ }^{4}$

Fica pois demonstrado que o sistema de saúde português ignora um grupo de pessoas e nega-lhes os cuidados de saúde a que têm direito, com subdiagnóstico e correspondente ausência de terapêutica. Para o mais céptico recordo aqui alguns dos problemas de saúde presentes em pessoas com trissomia $21^{2,3}$ e os que estavam identificados nos 209 adultos residentes na grande Lisboa ${ }^{1}$ : surdez de transmissão ou neurossensorial ( 70 a $75 \%$ vs ausência de qualquer referência); alterações da visão (60\% vs ausência de qualquer referência); apneia obstrutiva do sono $(50 \%$ vs ausência de qualquer referência); hipotireoidismo (10 a $40 \%$ vs $7 \%$ ); e doença celíaca ( $5 \%$ vs ausência de qualquer referência).

Espero que o artigo de Paula Breia et al, não só permita que todos os adultos com trissomia 21 tenham acesso aos cuidados de vigilância médica recomendados como promova o acesso aos mesmos de todas as pessoas com outros diagnósticos, em particular de uma doença rara.

3. Smith DS. Health care management of adults with Down Syndrome. Am Fam Physician. 2001;64:1031-8.

4. Nunes P, Sassetti L. Transferência ou transição? A passagem da pediatria para a medicina de adultos. Saúde Infantil. 2010;32:121-4.

\footnotetext{
1. Presidente da Direção. Colégio da Especialidade de Genética Médica. Ordem dos Médicos. Lisboa. Portugal

2. Serviço de Genética Médica. Hospital Pediátrico. Centro Hospitalar e Universitário de Coimbra. Coimbra. Portugal.

3. Clínica Universitária de Pediatria. Faculdade de Medicina. Universidade de Coimbra. Portugal.

Recebido: 09 de Junho de 2014 - Aceite: 09 de Junho 2014 | Copyright @ Ordem dos Médicos 2014
} 


\section{A Propósito do Artigo "Adults with Down Syndrome: Characterization of a Portuguese Sample" \\ Acta Med Port 2014:27:281-281}

Publicado pela Acta Médica Portuguesa, a Revista Científica da Ordem dos Médicos

Av. Almirante Gago Coutinho, 151

1749-084 Lisboa, Portugal.

Tel: +351218428215

E-mail: submissao@actamedicaportuguesa.com

www.actamedicaportuguesa.com

ISSN:0870-399X | e-ISSN: 1646-0758

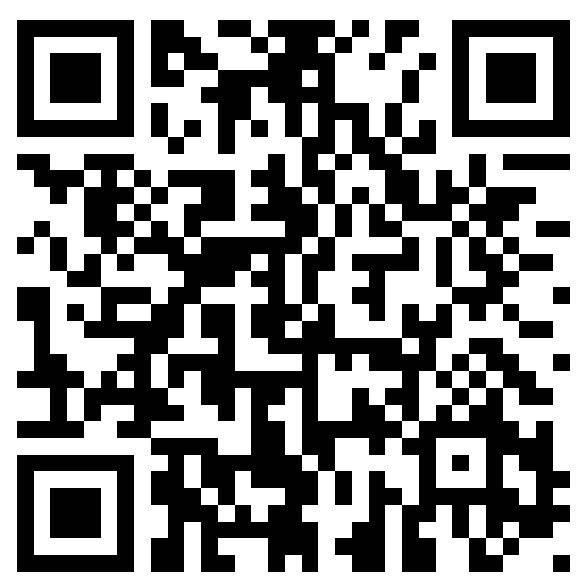

